\title{
CIRCULATORY AND RESPIRATORY EFFECTS OF GUANETHIDIN
}

\author{
BY \\ R. ROKSETH, O. STORSTEIN, A. VOLL, A. M. ABRAHAMSEN, AND J. OFSTAD \\ From the Cardiological Laboratory, Medical Department A, University Hospital, Oslo, and Medical Department A, \\ University Hospital, Bergen \\ Received September 11, 1961
}

Guanethidin has been shown by Maxwell et al. (1959) to be a potent antihypertensive agent in dogs, and by Page and Dustan (1959) and Leishman et al. (1959) to be hypotensive in human patients. It selectively inhibits sympathetic activity, probably by blocking postganglionic adrenergic neurones.

The intention of this study is to examine the acute effect of guanethidin in patients with increased pulmonary vascular resistance. Besides the possible practical implications, the subject may also be of theoretical interest as the nervous regulation of the pulmonary circulation is little known. Taylor and Donald (1960) found in hypertensive patients that bretylium tosylate, another sympathetic inhibitor, caused a rise in pulmonary vascular resistance, and they concluded that it appeared to be contra-indicated in patients with heart disease. Guanethidin, 20-40 mgm. intravenously, gave in five hypertensive patients no consistent change in pulmonary artery pressures or cardiac output. Lichtlen et al. (1960) observed that 20-30 mgm. guanethidin in five hypertensive patients caused a decrease in systemic blood pressure, peripheral vascular resistance, and pulmonary artery pressure after tilting feet down, while the cardiac output was little changed. In the horizontal position the pulmonary artery pressure again rose to previous values while the cardiac output increased above the initial value, and the peripheral resistance remained low. They attribute the fall in blood pressure to a reduction of peripheral vascular resistance. Dollery et al. (1961), studying the hæmodynamic response to guanethidin, noted in 7 of 11 patients a fall in blood pressure accompanied by a fall in cardiac output, when they were tilted feet down.

The clinical use of adrenergic blocking agents presents many problems. Besides sudden hypotension, and syncope during exercise, unexplained dyspnœa and severe muscular fatigue may be met with during treatment. On the other hand there are clinical reports of a beneficial effect on pulmonary œdema in hypertensive patients (Dollery et al., 1960).

\section{MATERIAL AND METHODS}

We studied 22 patients during routine diagnostic heart catheterization. Seventeen had mitral stenosis, one had myxoma of the left auricle and three had pulmonary hypertension from other causes. In one patient the pressures in the pulmonary circulation were normal. There were 16 women and $6 \mathrm{men}$, aged 31 to 56 years. Two patients had a diastolic pressure above $100 \mathrm{~mm}$. $\mathrm{Hg}$, the others were normotensive. They were examined in the supine position before breakfast and after having taken a barbiturate, $0 \cdot 10 \mathrm{gm}$. allypropymal $®$ at least one hour previously. Pressures in the pulmonary circulation were recorded by means of an Elema strain gauge electromanometer and four-channelled direct writing electrocardiograph. The zero level was the fourth intercostal space in the anterior axillary line. A Cournand needle was placed in the femoral artery, and the cardiac output was estimated in 17 patients, using the Fick principle, after stabilization of blood pressure and 
pulmonary artery pressure. Expired air was collected in a Douglas bag for three minutes and analysed for oxygen and carbon dioxide content by the micro-Scholander method. Oxygen saturation of the blood samples was measured spectrophotometrically employing the method of Gordy and Drabkin (1957). Arterial pH was measured with a glass electrode (Metrohm A.G. Herisau, Type 300 ), and arterial $\mathrm{pCO}_{2}$ was calculated from $\mathrm{pH}$ and $\mathrm{CO}_{2}$ content (manometric van Slyke), using the nomogram of Singer and Hastings (1948). Blood pressures were measured by arm cuff in 15, and recorded directly through the needle in the femoral artery in 7 patients. The heart rate was read from the electrocardiogram. Guanethidin ("Ismelin"), $10 \mathrm{mgm}$., diluted in saline to $2 \mathrm{ml}$., was then injected through the catheter in the pulmonary artery within two minutes. The pressure recordings were repeated every two minutes, and a second determination of cardiac output was done 15-18 minutes after the injection. After 20 to 25 minutes the catheter was withdrawn, but the brachial artery pressure was controlled by cuff for three to five hours.

\section{RESULTS}

The circulatory effects $15-20$ minutes after the injection of guanethidin are seen in Table I. There was a slight but consistent reduction of mean systemic blood pressure, mean pulmonary

TABLE I

Circulatory EfFEcts of GuANETHidin

\begin{tabular}{|c|c|c|c|c|c|c|}
\hline \multirow{2}{*}{$\begin{array}{l}\text { No. of } \\
\text { patients }\end{array}$} & & \multicolumn{2}{|c|}{ Mean values } & \multirow[b]{2}{*}{ Difference } & \multirow[b]{2}{*}{$\mathrm{t}$} & \multirow[b]{2}{*}{$\mathbf{P}$} \\
\hline & & Before & After & & & \\
\hline $\begin{array}{l}22 \\
22 \\
14 \\
17 \\
22 \\
17 \\
11 \\
17 \\
17\end{array}$ & $\begin{array}{l}\text { Mean blood pressure } \\
\text { Mean pulmonary arterial pressure } \\
\text { Mean pulmonary capillary pressure } \\
\text { Cardiac Index } \\
\text { Heart rate } \\
\text { Total peripheral resistance } \\
\text { Pulmonary arterial resistance } \\
\text { Stroke volume } \\
\text { A-V oxygen difference }\end{array}$ & $\begin{array}{l}93 \cdot 6 \\
34 \cdot 2 \\
18 \cdot 6 \\
2 \cdot 71 \\
76 \\
1951 \\
240 \\
63 \\
47 \cdot 3\end{array}$ & $\begin{array}{l}86 \cdot 6 \\
30 \cdot 6 \\
15 \cdot 0 \\
2 \cdot 39 \\
72 \\
2023 \\
267 \\
60 \\
50 \cdot 3\end{array}$ & $\begin{array}{l}-7 \mathrm{~mm} . \mathrm{Hg} \\
-3.6 \mathrm{~mm} . \mathrm{Hg} \\
-3.6 \mathrm{~mm} . \mathrm{Hg} \\
-0.321 / \mathrm{min} . / \mathrm{m} .^{2} \\
-4 \mathrm{per} \mathrm{min} . \\
+72 \mathrm{dyn} . \mathrm{sec} . \mathrm{cm} \cdot{ }^{-5} \\
+27 \text { dyn. sec. cm. } \\
+3 \\
-3 \mathrm{ml} . \\
+3.0 \mathrm{ml} . / 1 .\end{array}$ & $\begin{array}{l}6 \cdot 247 \\
3 \cdot 541 \\
2 \cdot 662 \\
4 \cdot 072 \\
2 \cdot 550\end{array}$ & $\begin{array}{l}<0.001 \\
<0.01 \\
<0.02 \\
<0.001 \\
<0.02\end{array}$ \\
\hline
\end{tabular}

artery pressure, and mean pulmonary capillary pressure. Fig. 1 illustrates the change in mean blood pressure measured by cuff in 15 patients during the first 18 minutes. There was no pressor phase as reported by others immediately after the injection of larger doses (Dollery et al., 1961). Fig. 2 shows the average change in blood pressure during two hours following the injection.

The cardiac output decreased in 14 patients, did not change in 2 and increased in 1 patient. The average decrease was about 12 per cent. There was no significant change in pulmonary or peripheral vascular resistance.

The stroke volume did not alter consistently, but in most patients there was a slowing of heart rate after guanethidin. In three patients bradycardia to $40-50$ beats per minute developed, 30 to 100 minutes after the injection. Bradycardia during guanethidin therapy has been previously reported by others, especially in digitalized patients (Dollery et al., 1960). Montuschi (1961) warns against the danger of cardiac arrest during operations on patients treated with guanethidin or bretylium tosylate and recommends a larger dose of atropin than usual in the premedication of these patients.

The effect on respiration is shown in Table II. There was a reduction in lung ventilation and in alveolar ventilation in 11 patients, but no change or a slight increase in 4 . The arterial oxygen saturation and carbon dioxide tension were unchanged. There were insignificant changes in the respiratory quotient and in the oxygen consumption as an indication of "steady state". 


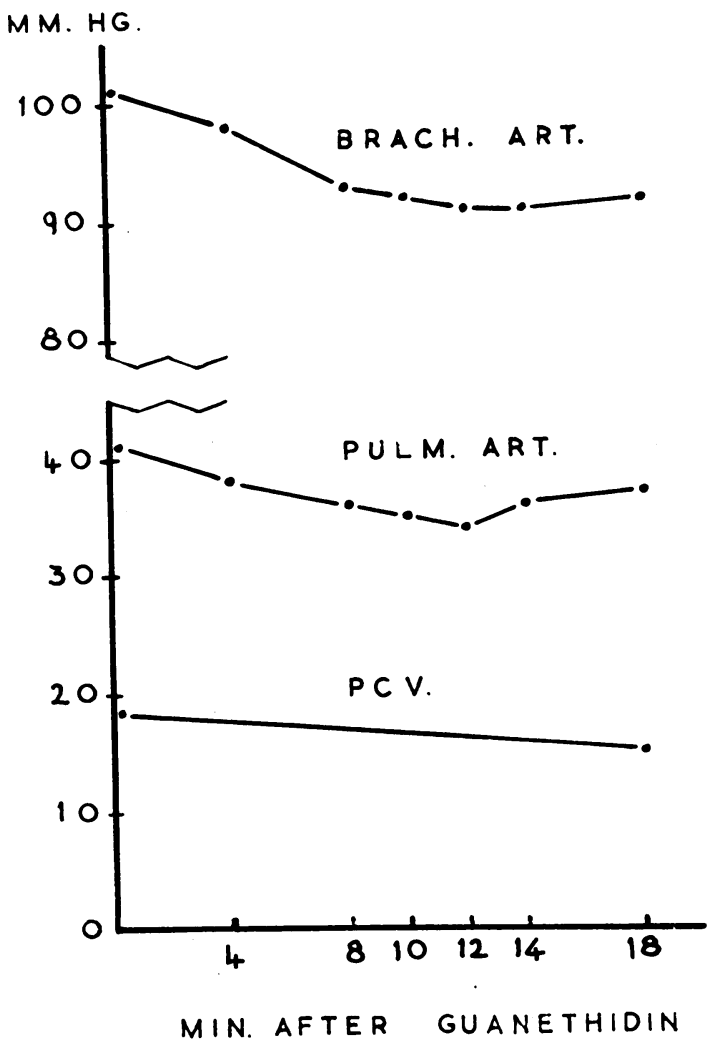

FIG. 1.-Illustrating the changes in mean blood pressure, pulmonary artery pressure and pulmonary capillary pressure following the intravenous injection of guanethidin.

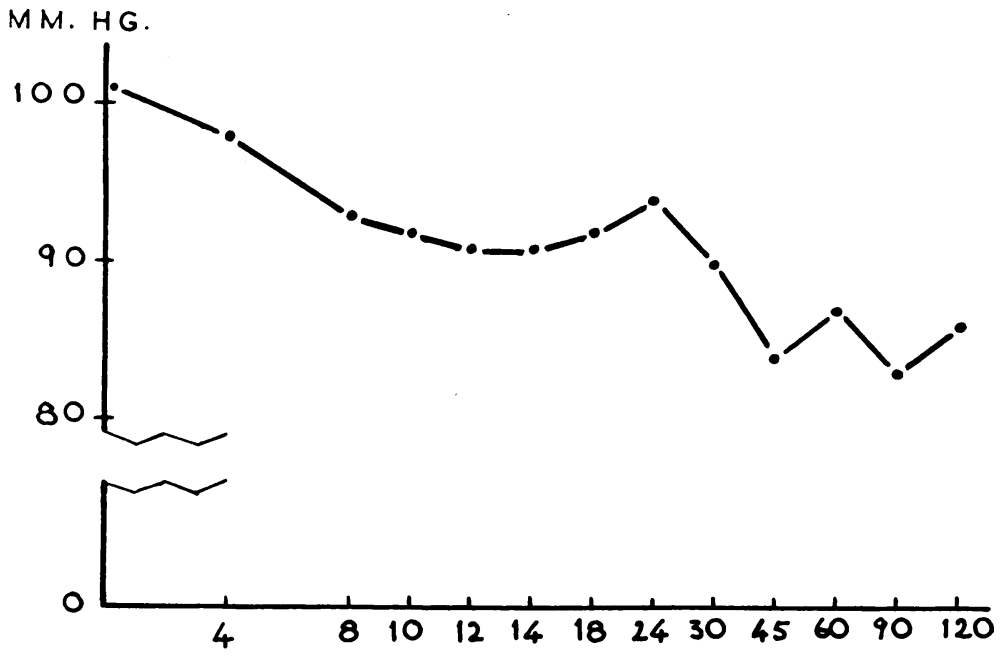

MIN. AFTER GUANETHIDIN

Fig. 2.-Shows the average change in brachial arterial mean pressure during two hours after intravenous injection of guanethidin. 
TABLE II

RESPIRATORY EFFECTS OF GUANETHIDIN

\begin{tabular}{|c|c|c|c|c|c|c|}
\hline \multirow{2}{*}{$\begin{array}{l}\text { No. of } \\
\text { patients }\end{array}$} & & \multicolumn{2}{|c|}{ Mean values } & \multirow[b]{2}{*}{ Difference } & \multirow[b]{2}{*}{$\mathbf{t}$} & \multirow[b]{2}{*}{$\mathbf{P}$} \\
\hline & & Before & After & & & \\
\hline $\begin{array}{l}15 \\
15 \\
22 \\
17 \\
15 \\
17 \\
15 \\
15\end{array}$ & $\begin{array}{l}\text { Lung ventilation } \\
\text { Alveolar ventilation } \\
\text { Respiratory rate } \\
\text { Arterial oxygen saturation } \\
\text { Carbon dioxide tension } \\
\text { Oxygen consumption } \\
\text { Respiratory quotient } \\
\text { Dead space }\end{array}$ & $\begin{array}{c}5 \cdot 55 \\
3 \cdot 09 \\
16 \\
94 \\
37 \cdot 6 \\
203 \\
0 \cdot 671 \\
157\end{array}$ & $\begin{array}{c}5 \cdot 01 \\
2 \cdot 70 \\
16 \\
94 \\
38 \cdot 2 \\
187 \\
0 \cdot 653 \\
163\end{array}$ & $\begin{array}{l}-0.54 \mathrm{l} / \mathrm{min} . \\
-0.39 \mathrm{l} / \mathrm{min} . \\
0 \text { per min. } \\
0 \text { per cent } \\
+0.6 \mathrm{~mm} . \mathrm{Hg} \\
-16 \mathrm{ml} . / \mathrm{min} . \\
-0.018 \\
+6 \mathrm{ml} .\end{array}$ & $\begin{array}{l}2 \cdot 240 \\
2 \cdot 381\end{array}$ & $\begin{array}{l}<0.02 \\
<0.02\end{array}$ \\
\hline
\end{tabular}

\section{Discussion}

Our observations indicate that the pressure reduction following guanethidin is probably due to a fall in cardiac output. This is in accordance with the results of Richardson et al. (1960). They found a similar reduction of cardiac output, estimated by dye dilution curves in hypertensive patients five to seven days after guanethidin administered intravenously. Maxwell et al. (1960) found in dogs 24 hours after the injection, a clear reduction in cardiac index as analysed from carotid pulse $\Im$ contours.

A change in cardiac output of 10-15 per cent does not usually cause a similar pressure change in the pulmonary circulation owing to the normal large distensibility of the pulmonary vascular bed. But in our patients with increased pulmonary vascular resistance and decreased vascular elasticity, small changes in cardiac output may result in pressure fluctuations.

The decrease in ventilation is interesting in the light of some animal experiments. Vernikos and Zaimis (1960) suggest that there was a reduction in the number of functioning muscle fibres during guanethidin treatment. Respiratory paralysis may be produced in cats by bretylium tosylate (Boura and Green, 1959). In man, dyspnœa and severe muscular weakness accompanied by abnormal electromyographic patterns is reported after bretylium tosylate (Campbell and Montuschi, 1960). Dollery et al. (1960) observed during guanethidin treatment tremor and muscular fasciculations in some patients and suggest a direct action on the motor neurone or the striated muscle itself.

The dyspnœa which sometimes occurs after these agents may be due to weakness of the respiratory muscles. In order to examine whether the reduction in ventilation might be due to a depressive effect on the respiratory centre we studied in 10 patients the ventilatory response to breathing 5 per 3 cent carbon dioxide before and after injection of $10 \mathrm{mgm}$. guanethidin intravenously. After the $\mathrm{O}$ resting ventilation had been recorded, the patients breathed a carbon dioxide gas mixture for 10 D minutes. The minute ventilation was determined by collecting expired air in a Tissot spirometer during the last 3 minutes. The procedure was repeated after the injection of guanethidin. None of the patients had lung diseases. The results are seen in Table III. There was no significant ${ }^{\circ}$ change in ventilatory response to carbon dioxide after guanethidin, which indicates that the reduction in ventilation was probably not caused by a depressive effect on the respiratory centre.

Gaffney (1961) found a positive inotropic effect of guanethidin in the heart-lung preparation, but a negative inotropic effect if the dog was treated previously with guanethidin. There may be some reason to believe that guanethidin has a depressive effect on both heart and skeletal muscles (Vernikos @ and Zaimis, 1960). Our results, however, give no direct proof of such an effect. The doses were 0 small, and the reduction in ventilation was not critical, as there were no consistent changes in arterial blood gas values. Taylor and Donald (1960) reported increase in ventilation in five patients after $\stackrel{\mathbb{Q}}{\Omega}$ larger doses of guanethidin. The stroke volume would be expected to decrease if there were a $\stackrel{\varnothing}{\perp}$ depressive effect on the contractile force of the heart muscle. In our patients there was a significant $\bar{Q}$ 
TABLE III

Ventilatory Response to CaRbon DioXide

BREATHING BEFORE AND AFTER GUANETHIDIN $(1 / \mathrm{min}$.

\begin{tabular}{|c|c|c|}
\hline Pat. no. & Before & After \\
\hline $\begin{array}{r}1 \\
2 \\
3 \\
4 \\
5 \\
6 \\
7 \\
8 \\
9 \\
10\end{array}$ & $\begin{array}{l}31 \cdot 2 \\
17 \cdot 5 \\
19 \cdot 3 \\
17 \cdot 7 \\
18 \cdot 7 \\
32 \cdot 0 \\
21 \cdot 1 \\
26 \cdot 9 \\
14 \cdot 7 \\
28 \cdot 0\end{array}$ & $\begin{array}{l}31 \cdot 5 \\
15 \cdot 0 \\
18 \cdot 8 \\
15 \cdot 3 \\
21 \cdot 3 \\
32 \cdot 3 \\
22 \cdot 3 \\
24 \cdot 1 \\
16 \cdot 8 \\
23 \cdot 7\end{array}$ \\
\hline Mean & $22 \cdot 7$ & $22 \cdot 1$ \\
\hline & \multicolumn{2}{|c|}{$\begin{array}{c}\text { Diff }-0.6 \\
t=0.771 \\
0.4<P<0.5\end{array}$} \\
\hline
\end{tabular}

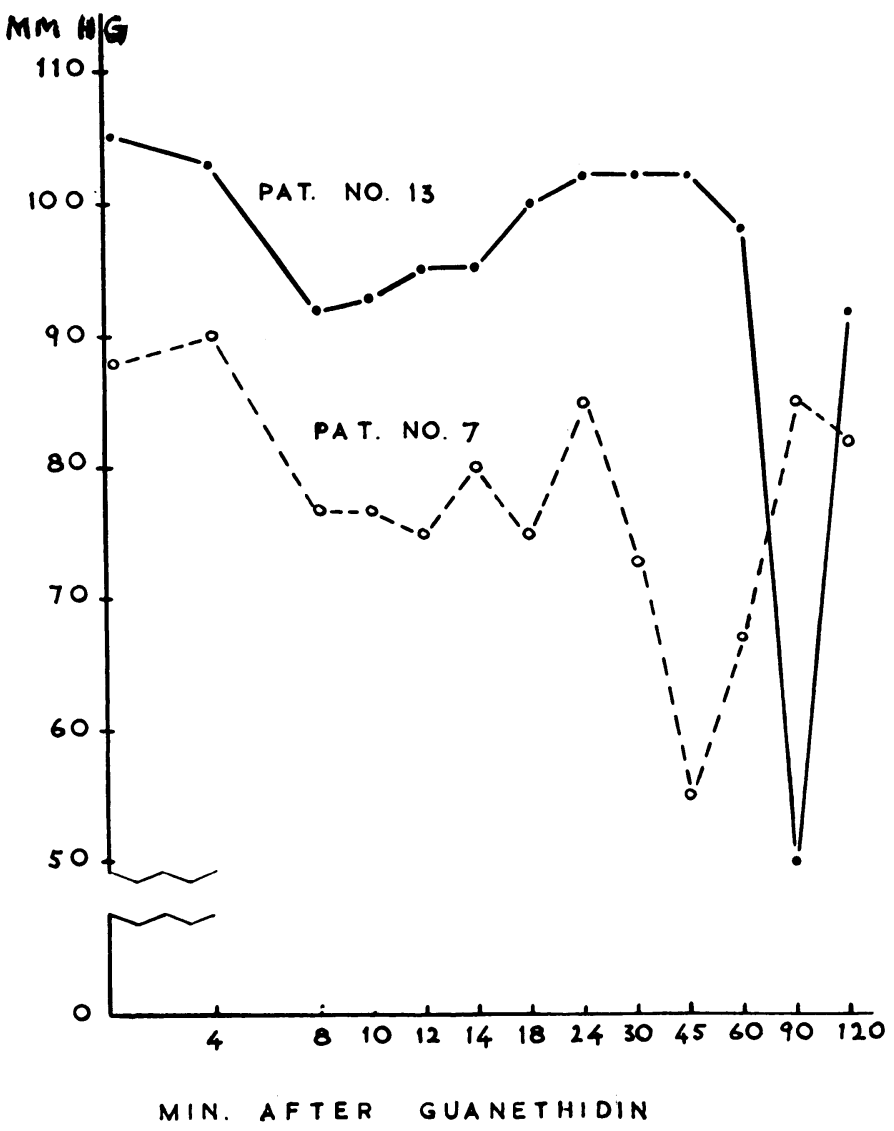

Fig. 3.-Showing the brachial arterial mean pressures following the intramuscular injection of ephedrine hydrochloride in patients with hypotension due to guanethidin. 


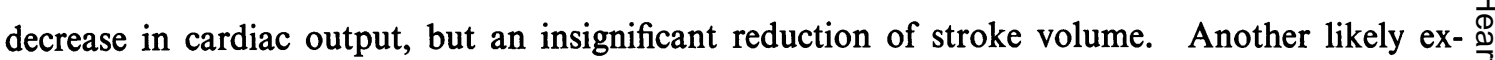
planation of the reduction in cardiac output is pooling of blood in the peripheral veins and reduced $c$ venous return to the heart (Richardson et al., 1960).

As regards unpleasant side effects, there was one complaint of nasal stuffiness, and in three patients the systolic blood pressure dropped to around 60 . Two of these patients were given $5 \mathrm{cg}$., and the third $10 \mathrm{cg}$. of ephedrine hydrochloride intramuscularly. The blood pressure rose in the former quite quickly to normal values, as illustrated in Fig. 3, and in the latter, who was a normotensive, to 200/120. This may seem surprising as guanethidin is reported to neutralize the hypertensive response in dogs to agents like ephedrine, amphetamine and tyramine (Page and Dustan, 1960). It may, however, be a question of dosage.

\section{CONTROLS}

By our methods the patients are their own controls. It would seem desirable also to repeat the recordings after the effect of guanethidin had subsided. This is, however, scarcely practical as the effect of a single dose of guanethidin lasts several days. It is not likely that systematic errors took $\vec{\oplus}$ place during the short time the examinations lasted. Guanethidin was injected through the catheter, and the patients were unaware of the time of injection. Before the injection we recorded two or three sets of pressures which did not vary significantly. Moreover, the whole procedure was repeated in six other patients with mitral stenosis, without guanethidin, and there were no consistent changes in pressure, heart rate, ventilation or cardiac output.

\section{SUMMARY}

Twenty-two patients, all but one with pulmonary hypertension, were given $10 \mathrm{mgm}$. guanethidin ("Ismelin") through a catheter in the pulmonary artery. There was a mean reduction in cardiac output of about 12 per cent, and a parallel reduction of pressures in the pulmonary arteries, pulmonary capillaries and systemic arteries. The calculated pulmonary and peripheral vascular resistances were unchanged. It is concluded from our examinations that the pressure drop following guanethidin is probably transmitted passively through a reduction in cardiac output.

Guanethidin also caused a decrease in ventilation, but the ventilatory response to carbon dioxide was not significantly changed, which may indicate a depressive effect on respiratory muscles.

The practical implications appear to be that pulmonary hypertension does not represent a contraindication to treatment with guanethidin. If an unexpectedly severe drop in systemic arterial pressure occurs, $5 \mathrm{cg}$. ephedrine hydrochloride intramuscularly seems to be an effective remedy. As the systolic blood pressure in three of our patients fell to about $60 \mathrm{~mm}$. $\mathrm{Hg}$ we advocate caution in the intravenous use of the drug and the starting of treatment with small doses.

\section{REFERENCES}

Boura, A. L. A., and Green, A. F. (1959). Brit. J. Pharmacol., 14, 536.

Campbell, E. D. R., and Montuschi, E. (1960). Lancet, 2, 789.

Dollery, C. T., Emslie-Smith, D., and Milne, M. D. (1960). Lancet, 2, 381.

, - and Shillingford, J. P. (1961). Lancet, 2, 331.

Gaffney, T. E. (1961). Circulat. Res., 9, 83.

Gordy, E., and Drabkin, D. L. (1957). J. Biol. Chem., 227, 285.

Leishman, A. W. D., Matthews, H. L., and Smith, A. J. (1959). Lancet, 2, 1044.

Lichtlen, P., Schaub, F., and Bühlmann, A. (1960). Dtsch. med. Wschr., 85, 1249.

Maxwell, R. A., Mull, R. P., and Plummer, A. J. (1959). Experientia, 15, 267.

, Plummer, A. J., Schneider, F., Povalski, H., and Daniel, A. I. (1960). J. Pharmacol. exp. Ther., $128,22$.

Montuschi, E. (1961). Lancet, 1, 224.

Page, I. H., and Dustan, H. P. (1959). J. Amer. med. Ass., 170, 1265.

Richardson, D. W., Wyso, E. M., Magee, J. H., and Cavell, G. C. (1960). Circulation, 22, 184.

Singer, R. B., and Hastings, A. B. (1948). Medicine, 27, 223.

Taylor, S. H. and Donald, K. W. (1960). Lancet, 2, 389.

Vernikos, J., and Zaimis, E. J. (1960). Lancet, 2, 787. 